\title{
LACAN X BUBER/PAZ: ENTRE O CONTINGENTE E O ETERNO
}

\author{
Silvia Simone ANSPACH*
}

RESUMO: Um confronto entre as idéias de Lacan de um lado e as de Buber e O. Paz de outro revela uma incompatibilidade absoluta de posições. Para Lacan, a unidade primordial é irresgatável e, aliás, jamais existiu, não passando de uma alucinação. O nascimento impõe ao sujeito uma condição de fragmentaridade. Toda a empresa humana se reduz à busca da unidade perdida, ao desejo, que visa a objetos que, produzirem um simulacro de gozo, preenchem uma ausência primeira com sua presença de maneira falseada. Inversamente, para Buber/Paz, o todo primordial se instala desde o princípio e jamais deixa de existir. A ação humana pode despertar este todo a cada momento, em cada ato e fato corriqueiro.

UNITERMOS: Todo primordial; luto primordial; objeto perdido; hiância; homem do humanismo; ordem simbólica; Outro absoluto; Ser; religião; palavra-princípio; EU-TU; outridade; EU-ISSO; aliedade; dialógico.

" (...) uma impossibilidade geradora de uma certa nostalgia busca o encontro impossivel com o objeto perdido, sendo que ele não é um objeto mas uma ausência." (11, p. 95)

(A. Vallejo e L. C. Magalhães, Lacan-Operadores de Leitura)

"Dessa maneira, para que eu os convide a se indignarem de que após tantos séculos de hipocrisia religiosa e de blefe filosófico, nada tenha sido ainda validamente articulado do que liga a metáfora à questão do ser e a metonímia à sua falta, seria preciso que, do objeto dessa indignação enquanto promotor e vítima, alguma coisa haja ai para corresponder-Ihes: a saber o homem do humanismo e a crença, irremediavelmente protestada de que ele obteve sobre suas intenções." (7, p. 259)

\section{(J. Lacan, Escritos)}

"O sentido do TU (...) não pode ser saciado, até que ele tenha encontrado o Tu infinito, que lhe estava presente desde o começo."

"Cada evento da relação é uma etapa que the possibilita um olhar sobre a relação completa."

" (...) os entes vivem em torno de você, mas ao se aproximar de qualquer um deles você atinge sempre o Ser."

"Através de cada Tu individualizado a palavra-princípio invoca o Tu eterno." (4, p. $93,18,87)$.

(M. Buber, Eue Tu)

*Professora de Literatura Inglesa e Americana na PUC-SP. Mestre em Lingüística Aplicada pela Universidade de Reading - Beveshire - Inglaterra. Doutoranda em Comunicação e Semiótica na PUC SP e Universidade do North Carolina at Chapel Hill. 


\begin{abstract}
" (...) um protesto contra o desterro de Deus como a procura da metade perdida, descida a essa região que nos comunica com o 'outro'."

" (...) ser o mundo sem cessar de ser ele mesmo. Nossa poesia é separação e tentativa de reunir o que foi separado. No poema, o ser e o desejo se pactuam por um instante, como o fruto e os lábios. Poesia, momentânea reconciliação: ontem, hoje, amanhã; aqui e ali; tu, eu, ele, nós. Tudo está presente: será presença. (8, p. 109, 122-123)
\end{abstract}

(O. Paz, Signos em Rotação)

Iniciando este trabalho através de uma longa epígrafe - colcha de retalhos tecida de idéias de três pensadores: Lacan, Buber e O. Paz, torno audivel e dou corpo ao diálogo surdo, porque nunca realizado, que se processa entre eles.

As citações apreendem discordâncias e consonâncias fundamentais que se expressam nesse diálogo imaginário e que repousam sobre elementos cruciais do pensamento dos três teóricos. As discordâncias separam Lacan dos dois outros autores; as concordâncias harmonizam as visões destes últimos num único acordo.

Lacan distoa do trio, ao sustentar que o todo primordial - a unidade mãe-filho - se perde com o nascimento - primeiro dilaceramento, primeira perda, primeira castração. $\mathrm{O}$ nascimento impõe ao sujeito uma condição de fragmentariedade e mutilação que permanece com ele ao longo de sua existência, instalando nele o desejo, a busca nostálgica do objeto primeiro - busca esta caracterizada em citação acima como "impossível", uma vez que o objeto "não é (nem mesmo) um objeto mas uma ausência". O sujeito desejante, na ânsia de resgatar a totalidade ou unidade primordial, busca objetos que, por produzirem um simulacro de gozo, preenchem a ausência com sua presença e substituem, de maneira falseada, o objeto primeiro - objeto "perdido", conforme vimos acima - e, segundo Fábio Hermann "nunca tido". O resgate da totalidade original (Nota a) não passa, portanto, de uma miragem, metáfora que rediz de forma camuflada a falta, a mutilação, a castração irremediável e sem retorno, presença sob a qual se esconde uma hiância, um vazio irreparável.

Não espanta, portanto, que a religião, se se compreende a mesma no sentido original da palavra, como "religação", reunião do que está separado na Unidade Divina, seja vista por Lacan como "hipocrisia", uma vez que, para ele, unidade e totalidade não passariam de miragens. Nem surpreende sua qualificação da tradição filosófica ocidental como "blefe", desde que esta repousa sobre a imagem do Sujeito cartesiano, do "homem do humanismo", Sujeito total, centro de toda a História, controlador de seu pensamento e, através deste pensamento, do universo que o cerca. Imagem que não passa de uma miragem, uma vez que o sujeito é irremediavelmente fragmento, desgarrado de uma unidade ou de um todo primordial jamais alcançado (ou tido) e alcançável e uma vez que ele se expressa através de uma linguagem ou "ordem simbólica" onde seu ser se aliena e se cinde. A linguagem é um Outro, "Outro absoluto (...) que pode anulá-lo a ele próprio" (7, p. 59).

Paradoxalmente, é pela linguagem que o sujeito é, mas é nela que se perde (7, p. 248). A linguagem "invoca a mentira como garantia da verdade na qual ele (o sujeito) subsiste (7, p. 256). O sujeito total cartesiano é, portanto, uma mentira unitária que camufla uma cisão irremediável. Além do mais, tal sujeito - sujeito pensante que controla suas ações e o mundo com seu pensamento onipotente - não comanda, mostra-nos Lacan, a linguagem - o instrumento que lhe permite pensar - mas é comandado por ela. Seu pensamento não está nele: É ele quem está no pensamento que, possibilitado pela linguagem o Outro que o fende - o aliena. A máxima cartesiana "Penso logo existo", que afirma o sujeito como dono, centro de seu pensar e existir, se desarticula para ressurgir no sistema lacaniano como "penso onde não existo, portanto existo onde não penso" e como 
"eu não sou, lá onde sou o joguete de meu pensamento; eu penso no que sou, lá onde não penso pensar" (7, p. 248).

Buber discordaria de Lacan, ao afirmar que a totalidade original, "o Ser", "a relação completa", "o Tu infinito", "o Tu eterno" em que o eu, sem deixar de ser eu integral se completa, "estava presente desde o começo" e jamais deixou de existir. Em cada ato e fato particular - nos atos e fatos que seriam compreendidos por Lacan como busca de substitutos do objeto primeiro - reside o Ser. Basta despertá-lo através da vivência radical, responsável e absoluta da dimensão dialógica da vida, da relação plena e total ou da palavra princípio "EU-TU" - binômio indissolúvel feito de partes tão íntegras e tão totais quanto o todo.

O. Paz alia-se a Buber e demonstra que, no indivíduo que não deixa de ser ele mesmo, lê-se o mundo; no microcosmo, o macrocosmo, a partir da vivência da "outridade" (8, p. 106 -107) que a experiência poética - experiência de "religação" (ou religião?) possibilita. Para Paz, a totalidade não está perdida: "tudo está presente". E onde ela está presente? Como para Buber, no "tu", no além. Além que se encontra no aqui e no agora; tu que comunga com cada eu.

Paz cita Breton: "la véritable existence est ailleurs" e endossa a citação, acrescentando: "Esse além está aqui, sempre aqui e neste momento. A verdadeira vida não se opõe à vida cotidiana nem à heróica; é a percepção do relampejar da 'outridade' em qualquer dos nossos atos, sem excluir os mais mesquinhos." (8, p. 106)

E completa:

“(...) sem deixar de ser. o que somos e (...) sem deixar de estar onde estamos, nosso verdadeiro ser está em outra parte. Somos outra parte. Em outra parte quer dizer: aqui, agora mesmo quando eu faço isto ou aquilo" (8, p. 107).

A voz de Buber soa com a de Paz em claro e afinado uníssono:

"'Que é que aconteceu aí de peculiar? Não era algo semelhante ao que me acontece todos os dias?' (...) 'Realmente, nada de peculiar aconteceu, é assim todos os dias, só que nós não estamos aí presentes todos os dias.' (...) As ondas do éter vibram sempre, mas, na maioria das vezes, estamos com nossos receptores desligados." (3, p. 43).

"(...) se santificas a vida, encontras o Deus vivo" $(4$, p. 92)

"A palavra-princípio EU-TU só pode ser proferida pelo ser em sua totalidade. (...) Não há EU em si, mas apenas o EU da palavra-princípio EU-TU (...)" (4, p. 4).

Ou seja, tanto para Paz quanto para Buber, (contrariamente a Lacan) a totalidade jamais deixou de existir. Antes que resgatada, deve ser despertada: devemos ter "os receptores ligados" para perceber a harmonia que empreendemos, cada fato com que nos relacionamos. Para ambos, o sujeito é pleno, "não deixa de ser eu", é "ser em sua totalidade". Não é sujeito mutilado, fragmentado e fragmentário como é concebido o sujeito lacaniano. Esta entidade plena, contingente, instalada no aqui e no agora, dialoga com o $\mathrm{Tu}$, com a outridade-plenitude cósmica divina. O incidente e temporal empatiza com o essencial e eterno e faz audivel sua inaudivel e intraduzivel voz. O cotidiano e corriqueiro revela o (Nota b) "verdadeiro Ser", o "Deus vivo" que está em outra parte, o TU da indissolúvel palavra-princípio EU-TU.

Para os dois, finalmente a palavra não apresenta uma feição puramente lingüística e, antes que cindir o sujeito, marca-Ihe a dimensão dialógica e totalizante, sintoniza-o à unidade existente "desde o começo", unidade primordial jamais perdida. Assim, diz-nos Buber: 


\begin{abstract}
"Signos nos acontecem sem cessar. Viver significa ser alvo da palavra dirigida (...) Se chamamos de Deus o emissor desta linguagem, então ele é sempre o Deus de um momento, um Deus do momento. (...) O Senhor da voz, o único." (3, p. 48).
\end{abstract}

E reforça Paz:

"A poesia não diz: eu sou tu: diz: meu eu és tu". (8, p. 102)

"(...) conjunção instantânea do eu e do tu. Poema: busca do tu." (8, p. 121)

As incompatibilidades entre a visão lacaniana de um lado e a buberiana e a de Paz de outro são evidentes: Aquilo que Paz e Buber lêem como possibilidade de transcendência, despertar de um todo jamais perdido, ressurreição do primeiro sempre existente e não nunca tido, religião ou "religamento", não passaria, para Lacan, de mera metáfora ou sintoma - tampão que sutura um vazio irrecuperável. Tudo se reduziria a uma miragem ou mentira que camufla a verdade única e última (jamais tida e, portanto, também em si um logrol que remonta à perda primordial. Como toda a perspectiva tradicional da filosofia ocidental e como toda a concepção humanista, como toda a religião, suas teorias não passariam de "hipocrisia" e "blefe".

Inversamente, para Buber e Paz seria a visão lacaniana que não passaria de um logro: Lacan em nada se afastaria dos seres "imunes à revelação" (3, p. 51), seres distraídos pelas aparências e contingências daquilo de fundamental que elas escondem. Seres que têm seus "receptores desligados" para "as ondas do éter", para o tudo que "está sempre presente" e "será (sempre) presença". Seres que, imersos na superfície, na materialidade dos corpos, são incapazes de "bater suas asas" para perceber nos jogos próprios a estes, "o fogo original" (3, p. 63). Seres que, na acepção de Buber, meramente "observam e anotam" os objetos enquanto objetos a eles externos e alheios, ao invés de "tomarem conhecimento íntimo dos mesmos" via uma relação de entrega plena, de resposta viva e vivida à palavra que vibra no seio de cada fenômeno qual pergunta. Seres que deixam de "ser alvo da palavra dirigida" (3, p. 41-43) e que ao fazê-lo, cessam de ter o privilégio de ter o mundo como palavra. Pois, quem cessa de proferir a resposta, cessa de ouvir a palavra. Lacan seria o EU da palavra-princípio EU-ISSO, eu que experiencia a realidade a nivel superficial, ao invés de vivê-la plena e relacionalmente, ou seja, ao invés de fazer-se o EU da palavra-princípio que conjura a completude ou "relação": EU-TU.

Chegamos ao fim desta exposição e ao seio e cerne de um antagonismo entre duas posições extremas. As duas posturas nos deixam em suspenso, obrigando-nos a uma permanente incerteza: Será a interpenetração dialética entre ambas uma totalidade real ou será sua totalidade mera miragem, mera invenção mentirosa que nos satisfaz falseadamente de nossa frustação em termos, no compartimento reservado às respostas, uma incógnita? A tensão entre as idéias de Lacan e Buber/Paz deixam-nos bem no centro deste impasse. $E$ da certeza de que qualquer certeza é suspensão, interrogação e, portanto, incerteza.

Inútil seria tentar traduzir o sistema lacaniano em termos buberianos e vice-versa. Conforme sabemos, seguindo o lingüista Ferdinand de Saussure (9), um sistema se organiza de maneira tal que, suprimida, acrescentada, permutada, alterada qualquer uma de suas partes, o todo se modifica. Verter um sistema em outro é sempre vertê-lo parcial e distorcidamente e, portanto, ao invés de traduzi-lo, reduzi-lo a algo que ele não é. Além do mais, creio ser saudável ao pensamento científico a atitude antidogmática, que questiona ser cada modelo científico $O$ modelo por excelência. Conforme demonstra a teoria do dialogismo bakhtiniana (1), a obra de T. S. Eliot (6), a de J. L. Borges (2), só para citar alguns autores, não há modelo privilegiado, mas uma confluência de modelos. Mesmo o modelo que parecer paradigmático materializa uma confluência de processos, atrai para si toda a tradição e toda a produção humana. 
Ao dizermos que a verdade é sempre parcial, estaríamos ecoando Lacan? Não. Para Lacan, o caráter parcial da verdade residiria no fato de que o dadó verdadeiro que se revela é mera ponta de um "iceberg" - do momento primordial, da verdade que é irresgatável. Temos de nos contentar com "pontas de icebergs" que o símbolo nos oferece, com "instantes de ver", instantes de revelação do que o fantasmático metaforiza e encobre.

Entendemos, inversamente, que a verdade é parcial porque é parte de uma confluência dialógica de onde o todo, o acordo - "acordo que nasce de desacordos" (10, ato V, cena 1), acordo maleável, dinâmico e vivo que herda sua natureza vital e dinâmica do diálogo-emerge. Parece-nos que, neste ponto, aproximamo-nos de Bakhtin, de Eliot, de Borges. E de Buber / Paz para quem o Ser se revela na dimensão dialógica (Nota c) da realidade, na outridade que dela se descortina, na natureza de confluência relacional que ela apresenta.

Lacan nos atacaria a todos, novamente, condenando nosso pensamento a ser metáfora do vazio primeiro, reelaboração do luto primordial. Ao condenar toda a empresa humana a ser reelaboração de tal luto, a ser vida que repete uma morte primeira (vida desvitalizada de fato e vista por nós com um sentido em si e não na morte a que oculta, porque somos vítimas do desejo e buscamos um simulacro de gozol para Buber / Paz novamente Lacan estaria se condenando a ser o EU da palavra-princípio EU-ISSO ou o vivente na dimensão da "aliedade" (8, p. 107). O EU da palavra EU-ISSO, o alienado, não vê na vida a ressurreição do Ser, a revivicação do TU que se dá na dimensão dialógica.

"Todo acontecer traz em si a eternidade", diz N. Lohfink, segundo citação de Haroldo de Campos (5). Ecoamos sua frase. E, ao fazê-lo, vemos o eterno esboçar uma "névoa de nadas" (Nota d) a miragem que Lacan leria no perene. Ficamos no centro do impasse: entre o eterno e o momentâneo, extingüivel. Entre o Ser e o nada. Entre o Ser e (como diria Lacan) a falta-a-ser.

\section{NOTAS}

(a) Hermann, F., em palestra proferida no curso de Extensão - "Abordagem da Articulação SexoLinguagem em Psicanálise" - 1ำ semestre de 1986, PUC/SP.

(b) No sentido de velar duas vezes e, neste velar, dialeticamente, desvelar.

(c) Cabe distingüir entre a noção de dialogismo para Bakhtin - entendida como polifonia de vozes textuais, confluência de posturas ou palimpsesto e a dimensão dialógica buberiana, onde o dialógico é a vivência da relação EU-TU, ou' o empatizar com o outro sem perder, na empatia, o caráter de eu e o resgate, na responsabilidade e reciprocidade absoluta da relação, da eternidade e completude do Ser.

d) No artigo citado em (5) acima, Haroldo discute sua tradução do "Qohélet" (Eclesiastes) e demonstra que optou pela tradução do "tema da 'nulificação' proclamado no refrão recorrente: 'havel havalim/vanitas vanitatum" por "névoa de nadas". 
ANSPACH, S. S. - Lacan X Buber / Paz: between the contingent and the eternal. Trans/Form/Ação, São Paulo, 9/10 : 49-54, 1986/87.

ABSTRACT: A comparison between Lacan's ideas on the one hand, and Buber's and Paz's on the other reveals an absolute incompatibility of positions. According to Lacan, an original unity cannot be recuperated and has never actually existed. Birth imposes a condition of incompleteness upon human beings, bringing about desire and a nostalgic search for a lost object. All human actions are reduced to a search for objects that produce a false satisfaction and joy and replace a basic emptiness with their presence. Conversely, for Buber/Paz, an original unity is established since the beginning and has never ceased to exist. Human actions can awake this unity at each and every moment and in each, and every fact and act of daily life.

KEY-WORDS: Primal unity; primal mourning; lost object; void; subject of humanism; symbolic order; absoIute Other; Being; religion; principle-word; I-THEE; otherness; I-THIS; alienation; dialogic.

\section{REFERÊNCIAS BIBLIOGRÁFICAS}

1. BAKHTIN, M. - Problemas da poética de Dostoiévski. Rio de Janeiro, Forense - Universitária, 1981.

2. BORGES, J. L. - Jorge Luis Borges: prosa completa. Barcelona, Bruguera, 1980.

3. BUBER, M. - Do diálogo e do dialógico. São Paulo, Perspectiva, 1982. (Coleção Debates).

4. BUBER, M. - Eu e Tu. São Paulo, Cortez e Moraes, 1979.

5. CAMPOS, H. de - Qohélet, O-Que-Sabe. Folha de São Paulo, Folhetim, 08/06/1986.

6. ELIOT, T. S. - Tradition and the individual talent. In: BRADLEY, et alii, org. - The American tradition in literature. New York, Grosset and Dunlap, 1967. .2.

7. LACAN, J. - Escritos. São Paulo, Perspectiva, 1978. (Coleção Debates).

8. PAZ, O. - Signos em rotação. São Paulo, Perspectiva, 1976. (Coleção Debates).

9. SAUSSURE, F. de - Curso de Lingüística Geral. São Paulo, Cultrix, 1977.

10. SHAKESPEARE, W. - A Midsummer Night's Dream. In: The Complete Works of William Shakespeare. Londres, Spring Books, 1970.

11. VALLEjo, A. \& MAgALhÃES, L. C. - Lacan: Operadores de Leitura. São Paulo, Perspectiva, 1981. (Coleção Debates). 